\title{
New Zealand's Monetary Conditions Index: A Critical Analysis
}

\author{
Stephen J. Burnell
}

$\mathrm{T}$

THE Reserve Bank of New Zcaland is currently responsible for keeping inflation within the $0-3$ per cent range. Before 1996 , it sought to achieve this by determining the interest rate on 90-day bills (short-term interbank loans). However, in an open economy there is a fundamental problem with targeting an interest rate. If the exchange rate suddenly falls, due to some exogenous shock, while the Reserve Bank maintains its interest rate target, the price of traded goods will rise and so boost the profits of exporters. It is likely, therefore, that both expected inflation and output will rise. So while the Reserve Bank maintains the interest rate, sudden shocks to the exchange rate may alter the expected inflation rate.

There are at least two ways to reconcile the Reserve Bank's ultimate objective of controlling inflation with the problem of exchange rate shocks. First, the interest rate target could respond to exchange rate shocks: for example, a fall in the exchange rate could lead to a rise in the interest rate target. Second, the interest rate target could be abandoned and replaced with a targeted set of exchange rates and interest rates. Announcing in advance how the interest rate target will respond to exchange rate shocks is equivalent to announcing a targeted set of exchange rates and interest rates.

For simple models of inflation, given the current economic situation, we can construct a function from exchange rates and interest rates to the expected inflation rate. For any given expected inflation rate (and current economic situation), we can construct the set of exchange rates and interest rates that will generate the specified inflation rate. As we change the expected inflation rate, we can construct a family of sets (one set for each expected inflation rate). We can describe this family of sets without having to explicitly mention the expected inflation rate; all we need to know is that each set corresponds to a particular expected inflation rate. We can now construct a function from the current economic situation to a family of sets of exchange rates and interest rates. Further, for simple models, as we change the current economic situation, the relevant family of sets will remain unchanged. That is, we can specify a particular set of exchange rates and interest rates, and then con-

'Until December 1996, the range was 0-2 per cent.

Stephen Burnell is Senior Lecturer in Economics and Finance at Victoria University of Wellington. 
struct an unambiguous function from the current economic situation to the expected inflation rate.

Given such a simple model, we can then assign a number to each set of exchange rates and interest rates. This generates a function, from exchange rates and interest rates to real numbers. We can call this function the monetary conditions index (MCI) for inflation. Given the current economic situation, for each value of the MCI we have a unique expected inflation rate. This enables the Reserve Bank to target the expected inflation rate by targeting the MCI (given the current economic situation).

\section{Monetary Conditions and Instruments}

In New Zealand, the instruments available to the Reserve Bank are (i) the Settlement Cash ${ }^{3}$ target; (ii) the supply of discountable securities; (iii) the discount margin; and (iv) the relationship between the interest rates for Settlement Cash and short-term bonds." These instruments were last changed in August 1995. Since that time, the interest rate on 90-day bills has fluctuated between 7 per cent and 10 per cent, while the MCI has fluctuated between 600 and 1,000. Clearly, changes in monetary conditions (and interest rates) can occur without changes in monetary instruments.

One explanation for this phenomenon is that the Reserve Bank announces (i) a monetary conditions target and (ii) a threat that if actual monetary conditions are not close to the target then it will change some of its instruments. For this strategy to yield the announced target, it is necessary that a change in monetary instruments forces a change in monetary conditions. For example, a reduction in the Settlement Cash target forces banks to the discount window more often, so bank profits fall. It may be that there are two ways in which this leads to a change in monetary conditions. First, if we ignore the Reserve Bank's target (and its threat), we have a function from monetary instruments to equilibrium nominal interest rates. A lowering of the Settlement Cash target may raise equilibrium interest rates, at least in the short term. This creates a natural tendency for banks to raise interest rates in re-

\footnotetext{
${ }^{2}$ The central banks of Canada, New Zealand, Norway, and Sweden each publish an MCI, although they are usually derived from output growth rather than inflation. See, for example, Freedman (1994); Hansson and Lindberg (1994); Nadal-de-Simone et al. (1996); Reserve Bank of New Zealand (1996a); Dennis (1997); Ericsson et al. (1997). The Bank of Canada has recently stopped using the MCI as a target.

Demand deposits held by trading banks at the Reserve Bank. Trading banks can never begin a working day with an overdraft.

See, for example, Reserve Bank of New Zealand (1996b).

${ }^{5}$ Guthrie and Wright (1998) develop a model in which the Reserve Bank achieves a targeted path for interest rates by simply announcing the path. The key assumption in their model is that the Reserve Bank can achieve any interest rate it desires through open market operations. Hence, the Reserve Bank's threat to enter the bond market (an open mouth operation) will ensure that the interest rate is always equal to its target.
} 
sponse to a lowering of the Settlement Cash target. Second, by lowering the profits of banks, the Reserve Bank is punishing them, and this punishment mechanism may be sufficient to ensure that banks follow the wishes of the Reserve Bank. If interest rates are too low, the Reserve Bank announces that it will continue lowering bank profits until interest rates rise; and as banks understand that the Reserve Bank can indeed lower their profits, they automatically comply. Such a punishment strategy is asymmetric: the Reserve Bank cannot threaten to increase bank profits until it is obeyed. Rather, it would seem to rely upon competitive forces to lower interest rates, and threats of punishment to raise them.

These stories have some appeal when the Reserve Bank's target is a nominal interest rate. Do they also have appeal when the target is a value for an MCI? In this case, banks may be punished for shocks to the exchange rate, even though they have no direct control over this price (although banks are responsible for most foreign exchange transactions).

\section{A Simple Illustrative Model of Monetary Conditions and Inflation ${ }^{6}$}

Consider a discrete-time model, ${ }^{7}$ with domestic and foreign sectors. Goods in the domestic economy are classified as traded or non-traded goods; traded goods are those that can be exported and imported. There are two nominal interest rates: the domestic rate and the foreign rate. Finally, the exchange rate is measured as the price of domestic currency in terms of foreign currency, so a fall in the exchange rate is a depreciation.

For all the variables, we will assume that expectations are rational: on average, the realised value today is equal to yesterday's expectation. Further, for simplicity, we will assume that there are no unexpected shocks involved in the determination of goods prices. This ensures that expected inflation rates have an extremely simple functional form.

The model has three equations. First, the expected domestic price of traded goods tomorrow is given by today's foreign price of traded goods, expressed in domestic currency. That is, domestic prices follow world prices, with a lag. Such a lag structure is needed to ensure that a shock to today's exchange rate has a direct impact on the expected inflation rate, but not upon today's price level.

Second, the expected price of non-traded goods is driven by (i) their current price; (ii) the expected domestic price of traded goods; and (iii) the current domestic nominal interest rate. The crucial feature of this functional form is the role of the nominal interest rate; an increase in the current interest rate implies a reduction in the expected price of non-traded goods. This is designed to capture the deflationary aspect of raising the nominal interest rate.

Third, the domestic price level is a weighted average of the prices of traded and non-traded goods.

\footnotetext{
See the Appendix for a mathematical representation.

${ }^{7}$ Time, written as date $t$, unfolds as $t=1,2,3 \ldots$
} 
From these three equations, an $\mathrm{MCI}$ (for inflation) can be constructed, as an increasing function of both the exchange rate and the interest rate. Hence, the expected domestic inflation rate (from date $t$ to date $[t+\Pi$ ), can be written as an increasing function of (i) the sequence of current and past foreign inflation rates; (ii) the sequence of historic values for the $\mathrm{MCl}$ (where the coefficients are constructed so as to eliminate historic domestic interest rates); and (iii) the exchange rate at date $[t-1]$. Further, the expected inflation rate is a decreasing function of the current monetary conditions target and the sequence of historic exchange rates (up until date $(t-2)$.

To control inflation, therefore, it is essential that today's monetary conditions target responds to movements along yesterday's monetary conditions target. For example, if there were a shock that caused yesterday's exchange rate to rise - with the monetary conditions targets, for yesterday and today, both fixed - then the expected inflation rate will rise. That is, a movement along yesterday's monetary conditions target will alter the expected inflation rate. This implies that the Reserve Bank's predictions of future monetary conditions targets will be constantly updated, in response to shocks to the exchange rate.

Note that the expected inflation rate is not a function of expected values; it is determined solely by historic and current variables. As will be seen in the next section, it is easy to construct variants of the model in which expectations do matter.

To complete the model, an uncovered interest rate parity equation is added. ${ }^{8}$ That is, the current domestic interest rate is an increasing function of the current exchange rate and the current foreign interest rate, but a decreasing function of the expected exchange rate. ${ }^{9}$ The equilibrium values for the expected inflation rate, the current exchange rate, and domestic interest rate can now be calculated as functions of (i) current inflation rates; (ii) last period's MCI; (iii) the current monetary conditions target; (iv) the current foreign interest rate; and (v) the expected exchange rate.

Given the expected exchange rate (and the foreign interest rate), an increase in the current monetary condition target implies that the current exchange rate and interest rate both rise, while the expected inflation rate falls. Further, given the expected exchange rate and the current monetary conditions target, an increase in the foreign interest rate implies that the current exchange rate falls, the domestic interest rate rises, and the expected inflation rate remains unchanged. The same result emerges if the expected exchange rate falls, with the foreign interest rate and the current monetary conditions target both fixed.

\footnotetext{
${ }^{8}$ An investor can hold either domestic or foreign bonds. Consider beginning and ending with domestic currency. One possibility is to buy domestic bonds, hold them until they mature and receive the payoff. Another possibility is to buy foreign currency, then purchase foreign bonds, hold them until they mature, receive the payoff and then convert back into domestic currency. The uncovered interest parity condition says that, on average, the two possibilities will yield the same payoff.

If the expected exchange rate is systematically higher than the forward rate (which is the price determined today and which yields the covered interest rate parity condition), then a risk premium term can be added. This would then imply that investors are risk-averse and reluctant to hold domestic bonds unless the expected yield - in foreign currency - is sufficiently high, relative to foreign bonds.
} 
Finally, the model assumes that the relative size of the traded goods sector does not change over time. However, if we think of traded goods as those whose domestic price is determined by foreign prices, then it is likely that the traded sector's size will be rising over time. As it becomes more important for the domestic economy, the shape of the MCI changes in an intuitive manner: the coefficient on the exchange rate rises, while the coefficient on the interest rate falls. That is, as the size of the traded goods sector rises, the inflationary impact of exchange rate shocks will rise, while the impact of interest rate shocks will fall. Note that it will be difficult to use historic data to construct an MCI for today's expected inflation rate, as the historic estimate for the size of the traded goods sector will be too small.

\section{A Model of Inflation Where the Future Matters ${ }^{10}$}

In the previous model, the assumption that the domestic price of traded goods is driven by the foreign price with a lag was crucial to establishing the results given. In this section, it is assumed that the foreign price instantaneously determines the domestic price of traded goods. All the other equations are as in the previous section. The MCI is now a decreasing function of the exchange rate and an increasing function of the interest rate: that is, an increase in today's exchange rate (with the interest rate fixed) will lower current prices (for both traded and non-traded goods) and the expected prices for non-traded goods, but leaves the expected price for traded goods unchanged. Hence the expected inflation rate will rise.

Let today be given by date $t$. The expected inflation rate (from date $t$, untll date $[t+1])$ can now be written as an increasing function of (i) the sequence of historic foreign inflation rates; (ii) the sequence of historic values for the MCI (which will be used to eliminate domestic interest rates); (iii) the sequence of historic exchange rates; and (iv) the expected forcign exchange rate. Further, the expected inflation rate is a decreasing function of the expected exchange rate and the current monetary conditions target.

This model has two characteristics that are different from the previous one. First, for any monetary conditions target, the exchange rate is an increasing function of the interest rate. Second, the future matters as the expected inflation rate is a function of the expected exchange rate.

Looking at the first characteristic, for the MCI, suppose that the magnitude of the coefficient for the interest rates exceeds that for the exchange rate. Given the expected inflation rate, the expected exchange rate, and the foreign interest rate, if the current monetary conditions target is increased, then the exchange rate and the interest rate will both rise; a tightening of monetary policy implies the interest rate rises and the exchange rate appreciates. If the foreign interest rate rises (with the

\footnotetext{
${ }^{10}$ See the Appendix for a mathematical representation. 11

This assumes that a one-off increase in the current price of non-traded goods will not yield a larger increase in the expected price of non-traded goods. Note that this assumption is necessary to ensure that, following a one-off shock, the changes in future prices are bounded.
} 
monetary conditions target and the expected exchange rate both fixed), then the exchange rate and the interest rate will both fall.

With regards to the second characteristic, if the expected exchange rate rises (with the monetary conditions target and the foreign interest rate both fixed), then the exchange rate and interest rate will both rise, while the expected inflation rate will fall. That is, an expected movement along tomorrow's monetary conditions target will alter the expected inflation rate.

These results imply a fundamental weakness of monetary conditions targeting. By announcing a targeted set of exchange rates and interest rates, the Reserve Bank signals that it does not care which point on the set is chosen by the market. But the Reserve Bank does care. To control inflation, it is necessary for the Reserve Bank to target a sequence of exchange rates and interest rates. It is not sufficient simply to target a sequence of values for the $\mathrm{MCI}$.

\section{Monetary Conditions Indices for Output}

Much of the empirical work on monetary conditions has focused on the growth of real output rather than on inflation.

For simplicity, suppose the expected growth rate for domestic output can be expressed as a function of (i) past and present domestic growth rates, as well as past, present, and expected (ii) foreign growth rates, (iii) domestic real interest rates, and (iv) real exchange rates. Let the real exchange rate be defined as a domestic price level - expressed in foreign currency - divided by a foreign price level. The chosen price level could be a GDP deflator or a traded goods price level. If the focus is on traded goods prices, then it implies that the law of one price ${ }^{13}$ need not hold (at least in the short term). Apparent arbitrage opportunities may disappear once transport costs, together with the time required to transport, are considered. Alternatively, arbitrage opportunities may exist, but new firms may be unable to exploit them because of the oligopolistic nature of the production, distribution, and retail sectors. For example, if the domestic price of an imported good is high, new firms may be reluctant to import it if they believe existing importers will engage in a price war to ensure new entrants can never make a profit. Similarly, if the domestic price of an import is low, firms may be reluctant to raise their price, as this may damage their reputation and reduce their market share (such a situation may emerge when demand for the good is low).

To describe output growth in more detail, it will be useful to make some assumptions concerning the timing of data. Output, at date $t$, is calculated for a period of time, such as three months. Assume that price data for date $t$ are gathered at the beginning of the period, before any output has been produced. Further, assume that prices will remain fairly constant during the period: they change only at the beginning of each period. This captures the idea that day-to-day fluctuations in

\footnotetext{
${ }^{12}$ See, for example, Ericsson et al. (1997). 13

After allowing for differences in tax rates across countries, the domestic price of traded goods, expressed in foreign currency, should equal the foreign price.
} 
relative prices are unimportant; the focus is on prices that seem likely to last for some period of time. ${ }^{14}$ Hence, at the beginning of period $t$, prices at date $t$ have already been observed, while output at date $t$ has not yet been produced. Expected output growth therefore refers to output at date $t$, relative to output at date $[t-l]$.

It is likely that the expected growth rate will be inversely related to both the expected domestic real interest rate and the current real exchange rate. An increase in the expected real interest rate will discourage investment by firms and the purchase of durables by households. Similarly, an increase in the current real exchange rate may discourage exports and encourage imports.

From the expected output growth equation, the terms involving the expected real interest rate and the current real exchange rate can be used to construct an MCI for output growth.

Two crucial questions emerge from this formulation of an MCI. First, why focus on the expected real interest rate and the current real exchange rate, rather than the nominal interest rate and the nominal exchange rate? It should be noted that the expected real interest rate can be expressed in terms of the current nominal interest rate and the expected inflation rate, while the real exchange rate is determined by the nominal exchange rate and price levels for domestic and foreign output. By focusing on nominal variables, the role of the expected inflation rate is highlighted. In particular, suppose the expected inllation rate is influenced by the current nominal exchange rate and/or the current nominal interest rate. In this case, constructing an MCI using nominal variables will yield a different functional form (and ratio of coefficients) than the index constructed using real variables.

Second, why focus on expected output growth rather than the expected inflation rate, especially as the Reserve Bank's goal is to achieve an inflation target? The main explanation offered is that the key determinant of continuing inflation is the so-called output gap (the difference between actual output and some measure of potential output). ${ }^{16}$ Clearly, controlling output growth is equivalent to controlling the output gap; given current output and expected potential output, there is a one-toone relationship between expected growth and the expected output gap. But why should the Reserve Bank care about continuing inflation, as opposed to the sequence of observed inflation rates?

Suppose that the Reserve Bank can indeed construct a well-defined MCI for real output growth at each date. A monetary policy can then be thought of as the specification of a monetary conditions target at each date, from today until the end of time.

Given the sequence of historical variables and the sequence of expected exogenous variables, the Reserve Bank considers the set of all feasible monetary policies, and then chooses the policy it likes best. That is, the Reserve Bank has some welldefined objective function that it seeks to maximise (subject to certain constraints).

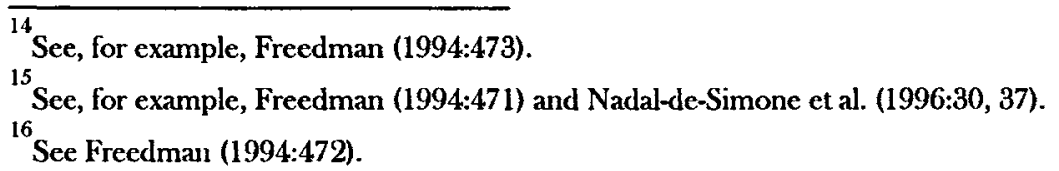


If the Reserve Bank's objective is to achieve its inflation target, at every date, then it will not 'distinguish between developments that affect the price level once and for all and those that affect the process of inflation' (Freedman, 1994:472). The Reserve Bank's MCI will be derived from the functional form for the expected inflation rate, while output growth will matter only if it is one of the influences on expected inflation. On the other hand, if the Reserve Bank's objective is to smooth output growth, as well as achieve its inflation target, then short-term deviations from the inflation target might occur, so long as these deviations encourage output smoothing. Put simply, the Reserve Bank will develop a concept of continuing inflation only if it is concerned with output smoothing. We may therefore infer that if the Reserve Bank targets an MCI for output growth, then output smoothing enters into the Bank's objective function. Note that in such a situation it is difficult to monitor the success of the Bank, as neither potential output nor continuing inflation is directly observable.

Finally, the expected growth rate — from today until tomorrow - will be influenced by a sequence of past, present, and expected real interest rates and a sequence of real exchange rates. For example, if the real interest rate is expected to fall, then firms may choose to delay investment. Similarly, if the real exchange rate is expected to rise (and this directly influences the domestic price of traded goods), consumers may delay the purchase of certain traded goods.

In the simplest case, the expected growth rate will be a function of a sequence of monetary conditions. To generate a targeted sequence of expected growth rates, therefore, it will be sufficient to specify a sequence of monetary conditions targets. More generally, however, the expected growth rate will be a function of a sequence of monetary conditions targets together with a sequence of real exchange rates (with the sequence of real interest rates captured by the monetary conditions targets). Hence, the Reserve Bank is concerned about more than just the sequence of monetary conditions targets; for each set of real exchange rates and real interest rates, it cares about the point at which the market will settle.

\section{Conclusion}

For simple models of expected inflation or output growth, the influence of the current exchange rate and interest rate can be captured by an $\mathrm{MCl}$. However, the shape of such an index (for example, expressing the exchange rate as a function of the interest rate) is highly sensitive to model specification. For example, in a model of expected inflation, if the domestic price of traded goods is determined by the foreign price, with a lag, then the exchange rate is a decreasing function of the interest rate. Alternatively, if the domestic price is instantaneously determined by the foreign price, then the exchange rate is an increasing function of the interest rate. The shape of the MCI influences the way the exchange rate and interest rate respond to shocks (for example, an increase in the foreign interest rate).

Even when the current exchange rate and the interest rate can be represented by an MCI, there is no reason why this will be true for either the past or the future. In particular, the past and the future can be represented by a sequence of monetary 
conditions targets, together with a sequence of exchange rates. Clearly, the empirical significance of this general result must be investigated. If the coefficients on the exchange rates are all fairly small, then for all practical purposes we can assume they are all zero. That is, we can approximate the true functional form by a function of the sequence of monetary conditions targets. If, on the other hand, some of the coefficients on the exchange rates are large, then the Reserve Bank must either abandon the concept of a monetary conditions target or recognise that it will have to revise its sequence of monetary conditions targets whenever the economy experiences a significant shock.

\section{Appendix: Mathematical Representations of Inflation Models}

A simple model of inflation. The variables are given by $\mathrm{i}_{\mathrm{t}}=$ domestic interest rate, $i{ }_{t}=$ foreign interest rate, $e_{t}=$ exchange rate, $p_{t}^{T}=$ price of traded goods, $\mathrm{p}_{t}{ }_{t}=$ price of non-traded good, $\mathrm{p}_{\mathrm{t}}=$ domestic price level, $\mathrm{p}_{\mathrm{t}}=$ foreign price for traded goods (inflation rates are $\bullet{ }_{t},{ }_{t},{ }_{t}$, and $\bullet *_{t}$, respectively). Variables involving time (i and $\bullet)$ are indexed by their initial date. Future variables $\left(\mathrm{e}_{t+1}, \bullet\right)$ can be thought of as expected variables. Finally, $m_{t}$ is a measure of the risk premium on domestic bonds.

$\mathrm{p}_{\mathrm{N}}^{\mathrm{T}}{ }_{\mathrm{i}+1}=\left[\mathrm{e}_{\mathrm{t}}\right]^{-1} \cdot \mathrm{p}^{*}{ }_{t}$,

$\mathrm{p}^{\mathrm{N}+1}=\left[\mathrm{p}_{\mathrm{t}}^{\mathrm{N}}\right]^{\mathrm{b}} \cdot\left[\mathrm{p}_{\mathrm{t}+1}^{\mathrm{T}}\right]^{1-\mathrm{b}} \cdot\left[1+\mathrm{i}_{\mathrm{t}}\right]^{-\mathrm{d}}$,

$\mathrm{p}_{\mathrm{t}+1}=\left[\mathrm{p}_{\mathrm{t}+1}^{\mathrm{T}}\right]^{\mathrm{a}} \cdot\left[\mathrm{p}_{\mathrm{t}+1}^{\mathrm{N}}\right]^{1-\mathrm{a}}$, and

$\left[1+i_{t}\right]=e_{t} \cdot\left[e_{t+1}\right]^{-1} \cdot\left[1+i^{*} t\right] \cdot\left[1+m_{t}\right]$.

Now, equations (1)-(3) yield:

$\log \left[1+\cdot t_{t}\right]=[a+(1-a) \cdot(1-b)] \cdot \log \left[1+\cdots *_{t-1}\right]$

$+[1-a] \cdot b \cdot[1-b] \cdot\left[\log \left(1+\cdot *_{t-2}\right)+b \cdot \log \left(1+\cdot *_{t-3}\right)+b^{2} \cdot \log \left(1+\cdot *_{t-4}\right)+\cdots \cdot\right]$

$-\mathbf{M}_{\mathrm{t}}+[1-\mathrm{b}] \cdot\left[\mathrm{M}_{\mathrm{t}-1}+\mathrm{b} \cdot \mathrm{M}_{\mathrm{t}-2}+\mathrm{b}^{2} \cdot \mathrm{M}_{\mathrm{t}-3}+\cdots\right]$

$+a \cdot b \cdot\left\{e_{t-1}-[1-b] \cdot\left[\log \left(e_{t-2}\right)+b \cdot \log \left(e_{t-3}\right)+b^{2} \cdot \log \left(e_{t-4}\right)+\cdots\right]\right\}$

where:

$M_{t}=[1-(1-a) \cdot b] \cdot \log \left[e_{t}\right]+[1-a] \cdot d \cdot \log \left[1+i_{t}\right]$

Further, equation (4) can be rewritten:

$\log \left[1+i_{t}\right]=\log \left[e_{t}\right]-\log \left[e_{t+1}\right]+\log \left[1+i_{t}\right]+\log \left[1+m_{t}\right]$

A model of inflation where the future matters

Equation (1) is now:

$\mathrm{p}^{\mathbf{T}}{ }_{\mathrm{t}+1}=\left[\mathrm{e}_{\mathrm{t}+1}\right]^{-1} \cdot \mathrm{p}^{*}{ }_{\mathrm{t}+1}$

Equations (2)-(4) are unchanged, yielding:

$\log \left[1+\cdot{ }_{t}\right]=[1-a] \cdot b \cdot[1-b] \cdot\left[\log \left(1+\cdot *_{t-1}\right)+b \cdot \log \left(1+\cdot *_{t-2}\right)\right.$ $\left.+b^{2} \cdot \log \left(1+\cdots *_{t-3}\right)+\cdots\right]$

$+[1-(1-a) \cdot b] \cdot[1-b] \cdot\left[\log \left(e_{t-1}\right)+b \cdot \log \left(e_{t-2}\right)+b^{2} \cdot \log \left(e_{t-3}\right)+\cdots\right]$

$+[1-(1-a) \cdot b] \cdot\left[\log \left(1+\cdot *_{t}\right)-\log \left(e_{t+1}\right)\right]-M_{t}+[1-b] \cdot\left[M_{t-1}+b \cdot M_{t-2}\right.$ $\left.+b^{2} \cdot M_{t-3}+\cdots\right]$

where

$M_{t}=[1-a] \cdot d \cdot \log \left[1+i_{t}\right]-\left[a+(1-a) \cdot(1-b)^{2}\right] \cdot \log \left[e_{t}\right]$ 


\section{References}

Dennis, R. (1997), A Measure of Monetary Conditions, Reserve Bank of New Zealand, Wellington (Discussion Paper No. G97/1).

Ericsson, N., E. Jansen, N. Kerbeshian \& R. Nymoen (1997), 'Understanding a Monetary Conditions Index', mimeo, Federal Reserve Board, Washington DC.

Freedman, C. (1994), 'The Use of Indicators and of the Monetary Conditions Index in Canada', pp. 458-76 in T. Balino \& C. Cottarelli (eds), Frameworks for Monetary Stability: Policy Issues and Country Experiences, International Monetary Fund, Washington DC.

Guthrie, G. \& J. Wright (1998), Market-implemented Monetary Policy with Open Mouth Operations, Department of Economics, University of Canterbury, Christchurch (Discussion Paper No. 98/02).

Hansson, B. \& H. Linberg (1994), 'Monetary Conditions Index - A Monetary Policy Indicator', Quarterly Review (Sveriges Riksbank), September: 12-17.

Nadal-de-Simone, F., R. Dennis \& P. Redward (1996), A Monetary Conditions Index for New Zealand, Reserve Bank of New Zealand, Wellington (Discussion Paper No. G96/2).

Reserve Bank of New Zealand (1996a), 'Summary Indicators of Monetary Conditions', Reserve Bank Bulletin 59: 223-8.

—_ (1996b), 'Implementing Monetary Policy in New Zealand', Reserve Bank Bulletin 59: 309-22.

I am grateful to two anonymous referees for many helpful comments on an earlier draft of this article. 